\title{
The Electromyographic Studies Before and After Carpal Tunnel Surgery
}

\author{
Mahmoud Farid MD \\ ${ }^{1}$ Associate professor of neurosurgery, Faculty of Medicine, Al A-zhar University
}

\begin{abstract}
Carpal tunnel syndrome is the most common peripheral entrapment neuropathy in humans. Its incidence is $1 \%$ for the general population and 5\% or more for workers with repetitive use of the hands and wrists(10). Women are three times more likely than men to develop CTS, which usually occurs only in adults. Most cases are idiopathic(23). The open surgical technique stills the gold standard procedure for the treatment of CTS (20).
\end{abstract}

Objective: The aim of this study was to assess the results of the pre- and postoperative electromyographic studies and their relationship to its clinical symptomatology before and after carpal tunnel decompression.

Methods: A retrospective study of 24 patients with CTS underwent open surgical decompression of median nerve at wrist and followed by electromyographic studies with assessment of post-operative clinical pictures.

Conclusion: Electromyography studies for carpal tunnel syndrome before and after surgery is not conclusive for diagnosis of carpal tunnel syndrome or recurrent carpal tunnel syndrome alone, the most important point of diagnosis is the clinical diagnosis of carpal tunnel with support of electromyography studies.

\section{INTRODUCTION}

Carpal Tunnel Syndrome (CTS) remains a puzzling and disabling condition commonly presented to Hand clinicians. It is a compressive neuropathy, which is defined as a mononeuropathy or radiculopathy caused by mechanical distortion produced by a compressive force (18). CTS is the most well-known and frequent form of median nerve entrapment (2), and accounts for $90 \%$ of all entrapment neuropathies (4). CTS is a neuropathy caused by entrapment of the median nerve at the level of the carpal tunnel, delimitated by the carpal bones and by the transverse carpal ligament (1). Physiological evidence indicates increased pressure within the carpal tunnel, and therefore decreased function of the median nerve at that level (2).

CTS is the most frequent entrapment neuropathy (1), believed to be present in 3.8\% of the general population (5). 1 in every 5 subjects who complains of symptoms such as pain, numbness and a tingling sensation in the hands is expected to have CTS based on clinical examination and electrophysiological testing (3), The primary features of CTS include pain in the hand, unpleasant tingling, pain or numbness in the distal distribution of the median nerve (thumb, index, middle finger and the radial side of the ring finger) $(18,22)$, and a reduction of the grip strength and function of the affected hand. Symptoms tend to be worse at night, and clumsiness is reported during the day with activities requiring wrist flexion (27).

CTS remains an idiopathic syndrome, but there are certain risk factors that have been associated with this condition. The most significant of these are environmental risk factors. Prolonged postures in extremes of wrist flexion or extension, repetitive use of the flexor muscles, and exposure to vibration are the primary exposures that have been reported (8).

There are several types of clinical neurophysiologic evaluations of the median nerve across the wrist. These include vibrometry threshold testing, current perception testing, symptom questionnaire (hand diagrams), and other quantitative sensory testing (Semmes-Weinstein monofilament testing, tactile sensation and two-point discrimination (17). These techniques are not as sensitive as NCS because they have considerable subjective components (26).

The use of ultrasound (US) has been implicated in the diagnosis of CTS because thickening of the median nerve, flattening of the nerve within the tunnel and bowing of the flexor retina culum are all features diagnostic of CTS (7). Several studies have concluded that cross sectional area is the most predictive measurement, but there is debate

${ }^{1}$ Corresponding Author: faridneuro@yahoo.com 


\section{American Research Journal of Medicine and Surgery, Volume 1, Issue 2, 2015}

ISSN 2379-8955

regarding the level within the tunnel that this measurement should be taken, and what constitutes abnormal values (25). The cross-sectional area of the median nerve has been used in US to classify the severity of CTS as normal, mild, moderate and severe (12).

The primary aim of this study is to evaluate the neurophysiologic study for the patients of carpal tunnel syndrome preoperative and postoperative and to show the different findings of postoperative changes.

\section{Patients And Methods}

Retrospective study from 2014- to 2015 of total 24 patients diagnosed as bilateral CTS was investigated by electromyography. All patients were treated by open surgical decompression of the involved median nerve. The following criteria were used for this study

Study:

A clinical diagnosis of CTS supported by Preoperative electromyographic examination

Open surgical decompression of the median nerve of the affected side

Postoperative clinical examinations at intervals of $1,3,6$.months

post-operative electromyographic examinations of both hands

In this study the technique of doing electromyography were not discussed but we concentrated on the results of electromyography pre-operative and post-operative

The median nerve sensory action potential amplitude, latency,and sensory conduction velocity (CV) were measured. Themedian nerve motor amplitude, distal motor latency (DML), and motor conduction velocity were measured using standardtechniques.

Padua et al classified EMG severity to(16).

Nerve conduction studies normal, no electrophysiologicalevidence of CTS;

$>$ Minimal, abnormal comparativetests;

Mild, prolonged median sensory latency (.3.5 MS), but normal median DML;

Moderate, prolonged mediansensory and DML latencies (>4.2);

Severe, absence of medianSNAP and prolonged or absent median DML.

Clinical diagnosis of CTS

\begin{tabular}{|c|c|l|l|l|l|l|}
\hline $\begin{array}{c}\text { Number of } \\
\text { patients }\end{array}$ & & $\begin{array}{l}\text { Preoperative } \\
\text { manifestations }\end{array}$ & $\begin{array}{l}\text { Right or left } \\
\text { hand }\end{array}$ & Associated & Type and sidePostoperative \\
medical problems & of surgery & manifestations(1-6 month) \\
\hline 2 & F & Numbness and pain & $\begin{array}{c}\text { Bilateral } \\
\text { more left }\end{array}$ & non & $\begin{array}{c}\text { left open } \\
\text { decompression }\end{array}$ & Improved \\
\hline 3 & F & Numbness and pain & $\begin{array}{c}\text { Bilateral } \\
\text { more left }\end{array}$ & $\begin{array}{c}\text { With cervical } \\
\text { manifestations }\end{array}$ & $\begin{array}{c}\text { Left open } \\
\text { decompression }\end{array}$ & The same as preoperative \\
\hline 8 & F & Numbness and pain & $\begin{array}{c}\text { Bilateral } \\
\text { more left }\end{array}$ & $\begin{array}{c}\text { Diabetics and } \\
\text { hypertensive }\end{array}$ & $\begin{array}{c}\text { Left open } \\
\text { decompression }\end{array}$ & Show some improvements \\
\hline 6 & F & Numbness and pain & $\begin{array}{c}\text { Bilateral } \\
\text { more right }\end{array}$ & Joints arthropathy & $\begin{array}{c}\text { right open } \\
\text { decompression }\end{array}$ & Show some improvements \\
\hline 1 & M & Numbness and pain & $\begin{array}{c}\text { Bilateral } \\
\text { more Right }\end{array}$ & non & $\begin{array}{c}\text { right open } \\
\text { decompression }\end{array}$ & Improved \\
\hline 4 & M & Numbness and pain & $\begin{array}{c}\text { Bilateral } \\
\text { more left }\end{array}$ & non & $\begin{array}{c}\text { left open } \\
\text { decompression }\end{array}$ & Improved \\
\hline
\end{tabular}

\section{RESULTS}

\subsection{Preoperative data}

From the 24 patients 19 patients ( $79 \%$ ) were females and 5 patients (21\%) were males the age ranged from 33 to 65 years old 


\section{American Research Journal of Medicine And Surgery, Volume 1, Issue 2, 2015 ISSN 2379-8955}

All patients were complaining of bilateral manifestations 6(25\%) female patients (more on right hands) and 13(54\%) female patient (more on left hands), 1(4\%) male patient (more on right hand) and 4(17\%) male patients (more on left hands).

$17(71 \%)$ patients were on left hands and $7(29 \%)$ patients were on the right hands

$17(71 \%)$ patients were associated with medical problems 3 females with cervical manifestations, 8 female patients were diabetics and hypertension, 6 females with joints arthropathy, and 7(29\%) patients were with no medical problems

Sensory symptoms (dysesthesia, numbness, and pain) were present preoperatively in all patients, while motor deficit patients were excluded.

\subsection{Operative data}

Release of median nerve at wrist for the treatment of carpal tunnel syndrome is a straightforward and satisfying procedure.

Phalen stated that the type of incision used in CTR surgery is of little importance provided that it does not cross the distal flexion crease of the wrist at a right angle (19).

Rengachary believed that the incision should be made from the wrist flexion crease extending curvilinear to a point in line with the distal border of the fully extended thumb. He also noted that the proximal incision should not cross the wrist flexion crease, thus preventing injury to the palmar cutaneous nerve (21).

Operative details were approximately the same for all patients

Some patients with moderate carpal tunnel compression with positive electromyography studies and carpal tunnel manifestations during surgery we found that there is no apparent compression

\subsection{Post-operative data}

Clinical examination during the follow-upperiod revealed marked improvement of 7(29\%) patients 2 female and 5 male with no medical problems, non to little improvement of 17(71\%) patient with medical problems and all of them were females.

Follow up with electromyography reveled even in the improved hands there are still median nerve compression manifestations from mild to moderate

\section{CASE STUDY}

Case No. 1 female patient 41 years old with no medical problems presented by numbness, and pain on her left hand EMG done for this patient shows severe carpal tunnel syndrome after surgery she followed up as outpatient for the first month she had some improvement but still complaining after 3 months she improved. EMG done for her shows mild carpal tunnel syndrome on the same hand

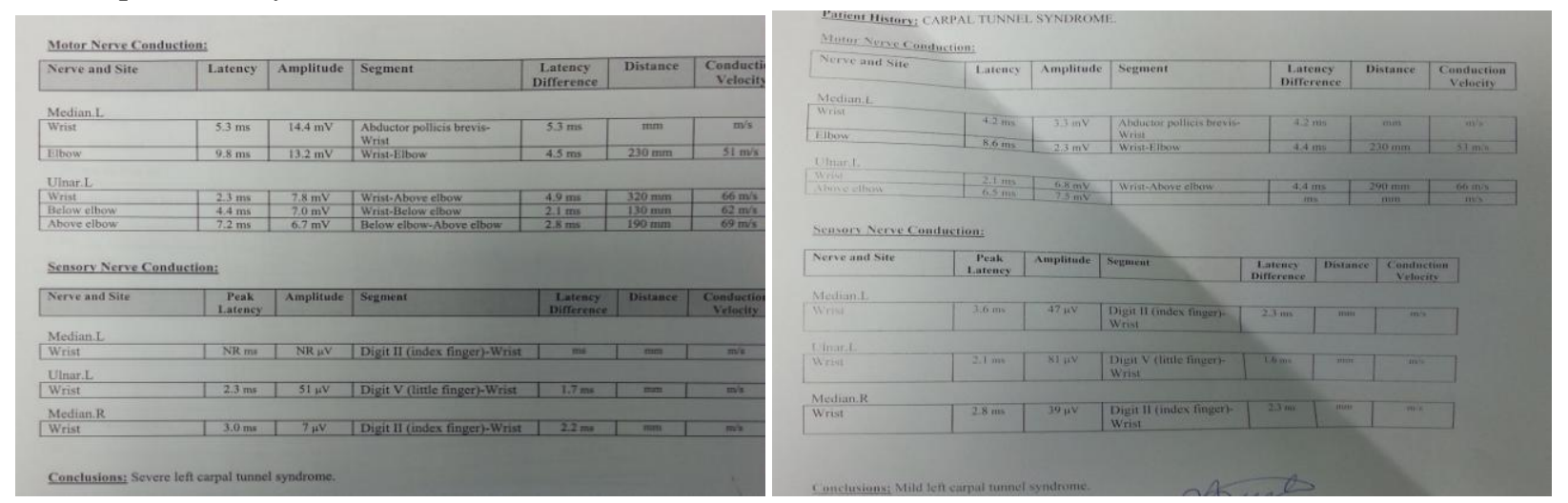

Case No. 2 Female patient with preoperative history of bilateral severe carpal tunnel syndrome

Followed after 1 month after left carpal tunnel decompression she is not improved and after 3, 6 months she better than before surgery

EMG before surgery shows severe carpal tunnel syndrome and after surgery shows bilateral carpal tunnel syndrome more severe on the right hand 


\section{American Research Journal of Medicine and Surgery, Volume 1, Issue 2, 2015 ISSN 2379-8955}
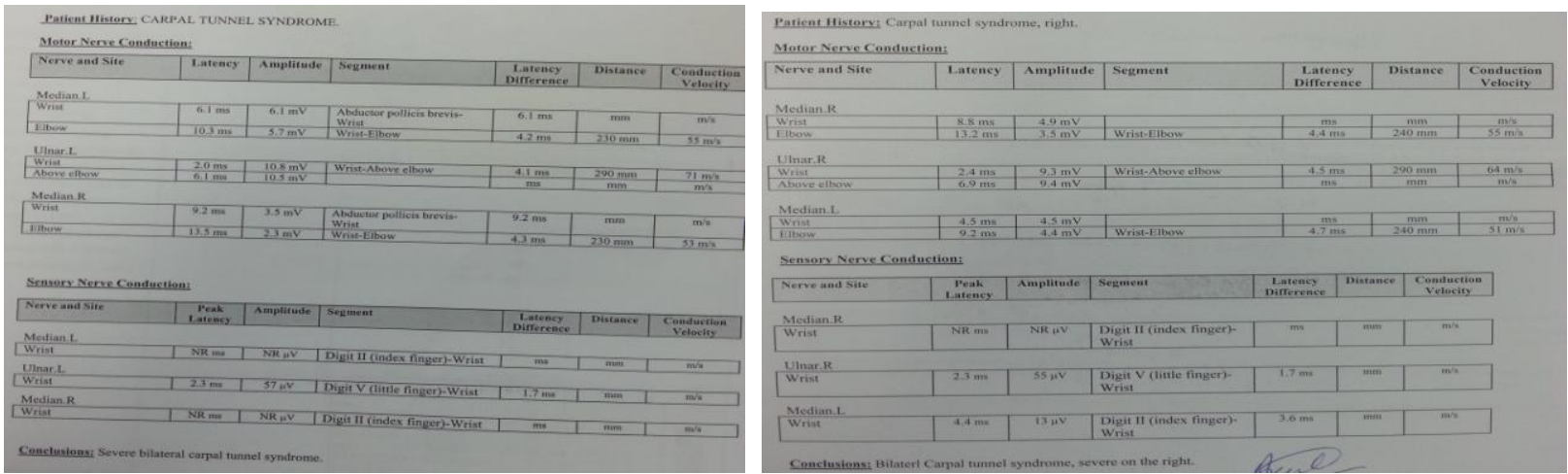

\section{DISCUSSION}

Carpal tunnel syndrome (CTS) is characterized by pain and sensory disturbance along the distribution of the median nerve. Thenar muscle atrophy may occur in the advanced stages of CTS. Tinel's sign and Phalen's test are the classical clinical indicators. A diagnosis is usually made on the basis of clinical symptoms and signs and confirmed using neural electrophysiological studies. The EPS reveals only the level of lesions; it does not provide local information about the nerve or the etiology of the disease.

Carpal tunnel syndrome (CTS) may be the presenting symptom of an underlying non diagnosed diseases such as diabetes mellitus, hypothyroidism or connective tissue diseaseso additional blood tests (glucose level, thyroidstimulating hormone level and erythrocyte sedimentation rate) are useful to detect these diseases(14).

So Idiopathic carpal tunnel syndrome (CTS) will not be the most common causes of carpal tunnel syndrome With the development of new and advanced imaging techniques like MRI, High-resolution sonography, new laboratory investigations and so on

Accurate diagnosis of carpal tunnel syndrome and its differentiation from other causes of hand morbidity is essential, particularly if the patient is a candidate for surgery (15).

According to Thomas, et al., motor conduction studies of the median nerve have been found valuable procedures in the diagnosis of carpal tunnel syndrome. Prolongation of the latency in response to stimulation of the motor fibers of the median nerve at the wrist was found in $67 \%$ of their patients(24).Although Electro diagnostic studies are highly specific, but they have a substantial false-negative rate of $10-20 \%$ (11).

Patients with CTS were classified according to electro diagnostic grading into:

Grade 0: Normal: Normal standard and comparative tests.

Grade 1: Minimal CTS: Normal standard tests, abnormal comparative tests.

Grade 2: Mild CTS: Abnormal sensory with a normal motor response that is, prolonged antidromic distal sensory latency (DSL) P2.9 ms to the second digit.

Grade 3: Moderate CTS: Abnormal median sensory and motor response that is, prolonged distal motor latency (DML) to abductor pollicis brevis (APB) is P4.2 ms but $66.5 \mathrm{~ms}$, and prolonged antidromic DSL with decreased amplitude sensory nerve action potential (SNAP).

Grade 4: Severe CTS: Absence of sensory response, abnormal distal motor latency to APB but still $<6.5 \mathrm{~ms}$ with decreased amplitude of compound muscle action potential (CMAP) and abnormal EMG activity in APB.

Grade 5: Very severe CTS: Terminal latency to APB $>6.5 \mathrm{~ms}$. Grade 6: Extremely severe CTS: Absence of median motor and sensory responses (surface motor potential from APB $<0.2 \mathrm{mV}$ amplitude) (6).

The most common complications with decompression the carpal tunnel is the phenomenon of pillar pain. Pillar pain is defined as tenderness on the base of the palm superficial to the carpal tunnel, sometimes concurrent with swelling, and without sensory disturbance(13).

Recurrent carpal tunnel syndrome are very rare and most probably due to wrong diagnosis before surgery due to associated lesions or other causes than compression of median nerve by transverse carpal ligaments 


\section{American Research Journal of Medicine And Surgery, Volume 1, Issue 2, 2015 ISSN 2379-8955}

Poor outcomes result from a number of factors including inaccurate diagnoses, iatrogenic surgical complications, and associated neuropathies(9).

\section{CONCluSions}

Electromyography studies for carpal tunnel syndrome before and after surgery is not conclusive for diagnosis of carpal tunnel syndrome or recurrent carpal tunnel syndrome alone, the most important point for diagnosis is the clinical diagnosis of carpal tunnel due to transverse carpal ligament compression or other medical causeswith support of electromyography studies so recurrent carpal tunnel syndrome due to transverse ligament affection is rare due to preoperative wrong diagnosis.

\section{REFERENCES}

[1] Alfonso C, Jann S, Massa R, Torreggiani A. Diagnosis, treatment and follow-up of the carpal tunnel syndrome: a review. NeurologSci 2010; 31(3): 243-52.

[2] American Academy of Orthopaedic Surgeons Work Group Panel.Clinical guidelines on diagnosis of carpal tunnel syndrome, 2007.

[3] Amirlak B, Upadhyaya K, Ahmed O, Wolff T, Tsai T, Scheker L. Median Nerve Entrapment. 1-11-2010. Internet Communication.[Accessed: 24/10/2011].

[4] Aroori S, Spence RA. Carpal tunnel syndrome. [Review] [135 refs]. Ulster Medical J 2008; 77(1): 6-17.

[5] Atroshi I, Gummesson C, Johnsson R, Ornstein E, Ranstam J, Rosen I. Prevalence of carpal tunnel syndrome in a general population. JAMA 1999; 282(2): 153-8.

[6] Bland JD. A neurophysiological grading scale for carpal tunnel syndrome. Muscle Nerve 2000; 23(8):1280-3.

[7] Buchberger W. Radiologic imaging of the carpal tunnel.Eur J Radiol 1997; 25: 112-7.

[8] Chell J, Stevens A, Davis TR. Work practices and histopathological changes in the tenosynovium and flexor retinaculum in carpal tunnel syndrome in women. J Bone Joint Surg Am 1999; 81(5): 868-70.

[9] Eason SY, Belsole RJ, Greene TL: Carpal tunnel release: analysis of suboptimal results. J Hand Surg (Br) 10:365369,1985

[10] Einhorn N, Leddy JP: Pitfalls of the endoscopic carpal tunnel release. OrthopClin North Am 27:373-380, 1996.

[11] Graham B, Regehr G, Naglie G, Wright JG. Development and validation of diagnostic criteria for carpal tunnel syndrome. J Hand Surg 2006; 31A (6):919-24.

[12] Karadag YS, Karadag O, Cicekli E, et al. Severity of carpal tunnel syndrome assessed with high frequency ultrasonography. RheumatolInt 2010; 30(6): 761-5.

[13] Ludlow KS, Merla JL, Cox JA, Hurst LN: Pillar pain as a postoperative complication of carpal tunnel release: a review of the literature. J Hand Ther 10:277-282, 1997.

[14] Maarten C, de Rijk, Frederique H, Vermeij Pieter A, van Doorn, Does a carpal tunnel syndrome predict an underlying disease? . J NeurolNeurosurg Psychiatry 2007;78:635-637.

[15] Mohammadi A, Afshar A, Etemadi A, Masoudi S, Baghizadeh A. Diagnostic value of cross-sectional area of median nerve in grading severity of carpal tunnel syndrome. Arch Iran Med 2010; 13(6):516-21.

[16] Padua L, Padua R, Aprile I, et al. Multiperspective follow-up of untreated carpal tunnel syndrome: a multicenter study. Neurology 2001; 56:1459-66.).

[17] Pelmear PL, Taylor W. Carpal tunnel syndrome and hand-arm vibration syndrome.A diagnostic enigma. [Review] [45 refs]. Arch Neurol 1994; 51(4): 416-20.

[18] Pfeffer GB, Gelberman RH, Boyes JH, Rydevik B. The history of carpal tunnel syndrome. J Hand Surg Br 1988; 13(1): 2834.

[19] Phalen G: The carpal tunnel syndrome. Clinical evaluation of 598 hands.ClinOrthop 83:2940, 1972.

[20] Prick JJ, Blaauw G, Vredeveld JW, Oosterloo SJ: Results of the carpal tunnel release. Eur J Neurol 10:733-736, 2003.

[21] Rengachary SS: Entrapment neuropathies, in Wilkins RH, Rengachary SS (eds): Neurosurgery. New York: McGraw-Hill, 1985, Vol 2, pp 17711776.

[22] Solomon L, Warwick D, Nayagam S. Apley's concise system of orthopaedics and fractures. NY: Oxford University Press 2005.

[23] Sternbach G. The carpal tunnel syndrome. J Emerg Med 1999; 17(3):519-23

[24] Thomas JE, Lambert EH, Cseuz KA: Electrodiagnostic aspects of the carpal tunnel syndrome. Arch Neurol 16:635-641, 1967.

[25] Wang LY. Best diagnostic criterion in high-resolution ultrasonography for carpal tunnel syndrome. Chang Gung Med J 2008; 31: 469-76. 
American Research Journal of Medicine and Surgery, Volume 1, Issue 2, 2015

ISSN 2379-8955

[26] Werner RA, Andary M. Carpal tunnel syndrome: pathophysiology and clinical neurophysiology. [Review] [71 refs].ClinNeurophysiol 2002; 113(9): 1373-81.

[27] Zyluk A, Kosovets L. An assessment of the sympathetic function within the hand in patients with carpal tunnel syndrome. J Hand SurgEur Vol 2010; 35(5): 402-8. 